\title{
Rate of acquired pulmonary vein stenosis after ablation of atrial fibrillation referred to electroanatomical mapping systems: Does it matter?
}

\author{
Katharina Schoene ${ }^{1,2}$, Arash Arya ${ }^{1}$, Cosima Jahnke ${ }^{1}$, Ingo Paetsch ${ }^{1}$, Nikolaos Dagres ${ }^{1}$, \\ Andreas Bollmann ${ }^{1}$, Gerhard Hindricks ${ }^{1,2}$, Philipp Sommer ${ }^{1}$ \\ ${ }^{1}$ Department of Electrophysiology, Heart Center, University of Leipzig, Germany \\ ${ }^{2}$ Leipzig Heart Institute GmbH, Leipzig, Germany
}

\begin{abstract}
Background: Thermal injury during radiofrequency ablation (RFA) of atrial fibrillation (AF) can lead to pulmonary vein stenosis (PVS). It is currently unclear if routine screening for PVS by imaging (echocardiography, computed tomography) is clinically meaningful and if there is a correlation between PVS and the electroanatomical mapping system (EAMS) used for the ablation procedure. It was therefore investigated in the current single center experience.

Methods: All patients from January 2004 to December 2016 with the diagnosis of PVS after interventional ablation of $A F$ by radiofrequency were retrospectively analyzed. From 2004 to 2007, transesophageal echocardiography was routinely performed as screening for RFA-acquired PVS (group A). Since 2008, diagnostics were only initiated in cases of clinical symptoms suggestive for PVS (group B).

Results: The overall PVS rate after interventional RFA for AF of the documented institution is $0.72 \%$ (70/9754). The incidence was not influenced by screening: group $A$ had a $0.74 \%$ PVS rate and group $B$ a $0.72 \%$ rate (NS). Referred to as the EAMS, there were significant differences: $20 / 4229$ (0.5\%) using CARTO $^{\circledast}, 48 / 4510$ (1.1\%) using EnSite ${ }^{\circledast}, 1 / 853$ (0.1\%) using MediGuide ${ }^{\circledast}$, and 1/162 (0.6\%) using Rhythmia ${ }^{\circledast}$. Since 2009, no significant difference between technologies was found.

Conclusions: The present analysis of 9754 procedures revealed 70 cases of PVS. The incidence of PVS is not related to screening but to the application of different EAMS. Possible explanations are technological backgrounds (magnetic vs. electrical), learning curves, operator experience, and work-flow differences. Furthermore, incorporation of new technologies seems to be associated with higher incidences of PVS before workflows are optimized. (Cardiol J 2019; 26, 5: 451-458)
\end{abstract}

Key words: pulmonary vein stenosis, radiofrequency ablation, atrial fibrillation, electroanatomical mapping system

\section{Introduction}

Thermal injury during radiofrequency ablation (RFA) of atrial fibrillation (AF) can lead to pulmonary vein stenosis (PVS), a rare but commonly known adverse event [1-4]. Severe symptoms such as dyspnea and hemoptysis may occur. Catheter-based interventional treatment for PVS still remains a challenging field [3, 5-9]. To improve anatomical understanding and to reduce radiation exposure during ablation procedures, electroanatomical mapping systems (EAMS) were introduced [10]. Because the electroanatomical map is not able to portray the complex anatomy of the left atrium in its entirety, an image integration step of a pre-recorded heart extracted from computed tomography

Address for correspondence: Katharina Schoene, MD, University of Leipzig - Heart Center, Department of Electrophysiology, Struempellstrasse 39, 04289 Leipzig, Germany, tel: + +49 341865 1413, fax: + +49 3418651460 , e-mail: Katharina.Schoene@helios-gesundheit.de 
(CT) or magnetic resonance imaging (MRI) was introduced [11]. The most widely used systems are CARTO $^{\circledast}$ (Biosense Webster, Baldwin Park, CA, USA) and EnSite ${ }^{\circledR}$ (Abbott/St. Jude Medical, St. Paul, MN, USA). The main technological difference between these three-dimensional (3D) mapping systems is the electromagnetic localization of catheters in $\mathrm{CARTO}^{\circledast}$ and the impedance-based approach of the EnSite NavX/Velocity ${ }^{\circledR}$ technology. Since the introduction of EnSite Precision ${ }^{\circledR}$ in 2016 providing magnetic catheter localization as well, no fundamental technological difference is present. It is unclear whether there is a relationship between the occurrence of PVS and the used EAMS during the ablation procedure for AF. Herein described, is a present single center experience.

\section{Methods}

From January 2004 to December 2016 all patients with the diagnosis of PVS after interventional ablation of AF by radiofrequency were collected. Cases with catheter-based cryoablation or intraoperative RFA for AF were excluded.

The study was approved by the local ethics committee and was done in accordance with the Declaration of Helsinki.

\section{Definition of PVS}

Minimal luminal diameter of stenosed pulmonary veins (PVs) was measured on multi-planar reformatted $3 \mathrm{D}$ angiographic datasets (by contrast enhanced CT or MRI) of pre- and post-ablation imaging and PVS was expressed as percentage of post- vs. pre-ablation luminal diameter reduction. The degree of PVS is classified as severe with luminal narrowing over $70 \%$, moderate for $50-70 \%$ narrowing, and mild for $<50 \%$ narrowing [12].

\section{Screening for PVS}

From 2004 to 2007, transesophageal echocardiography (TEE) was performed as routine screening for RFA-acquired PVS. The time of screening TEE was between 6 and 12 months after $\mathrm{PV}$ isolation or at the time of new symptoms suggestive of PVS. In cases of abnormal echo findings for PVs such as an accelerated peak flow over $1 \mathrm{~m} / \mathrm{s}$, a subsequent contrast enhanced CT or MRI timed for opacification of the PVs was performed to confirm and quantify the PVS. Also, in case of insufficient TEE quality, but typical symptoms suggestive for PVS, a subsequent imaging diagnostic was initiated.

Due to the low number of detected PVS and the logistic efforts required, routine screening was stopped. Since 2008, diagnostics were initiated only in cases of clinical symptoms suggestive for PVS. CT, MRI and/or PV angiography were the imaging methods used at this time. During this period, PVS of asymptomatic patients were detected as incidental findings in the context of re-ablation procedures.

\section{Ablation procedure}

The present ablation approach has been previously described [13]. Briefly, interventional RFA for $\mathrm{AF}$ at the documented institution is performed under analgosedation. After the transseptal approach, the PVs are isolated point-by-point with an irrigated tip catheter using radiofrequency as the energy source. The ablation line is made antral circumferential around the left- and rightsided PVs. Ablation inside the PVs was avoided. Additional ablation lines were performed at the discretion of the operator. Catheter navigation was supported by fluoroscopy and 3D EAMS. The choice of mapping tool and ablation catheter was at operator discretion. Intracardiac ultrasound guidance was not used.

\section{EAMS - CARTO ${ }^{\circledR}$}

At the documented institution, CARTO $\mathrm{XP}^{\circledR}$ was introduced in 1998. CARTO ${ }^{\circledR}$ works based on a magnetic field generated by a location pad placed under the patient's chest [14]. Sensors embedded in the catheter tip enable catheter localization. A further sensor on the patient's skin is used as a location reference. With further improvement of the system $\left(\mathrm{CARTO}^{\circledR}\right)$ by a combination of magnetic and current-based technology, visualization of multiple catheters has been available since 2009. In contrast to the EnSite NavX ${ }^{\circledR}$ system, the CARTO ${ }^{\circledR}$ allowed from the onset a reconstruction of the PVs as well as the whole atrium in one map (initially as point-by-point with CARTO $\mathrm{XP}^{\circledast}$ and later as fast anatomical mapping sampled by roving the catheter supported by CARTO $^{\circledR}$ ). Since 2005 , it is possible to merge the surfaces of a pre-recorded CT or MRI with the reconstructed map by the CARTOmerge ${ }^{\circledR}$ software. Further registration steps are not necessary (Fig. 1: 1A-D).

\section{EAMS - EnSite ${ }^{\circledR}$}

EnSite NavX ${ }^{\circledast}$ has been in use since 2005 in the present institution. The system works based on an electric field created by six skin electrodes in three orthogonal planes [15]. Catheter localization is implemented by an impedance gradient in relation to a reference electrode. Later, for com- 


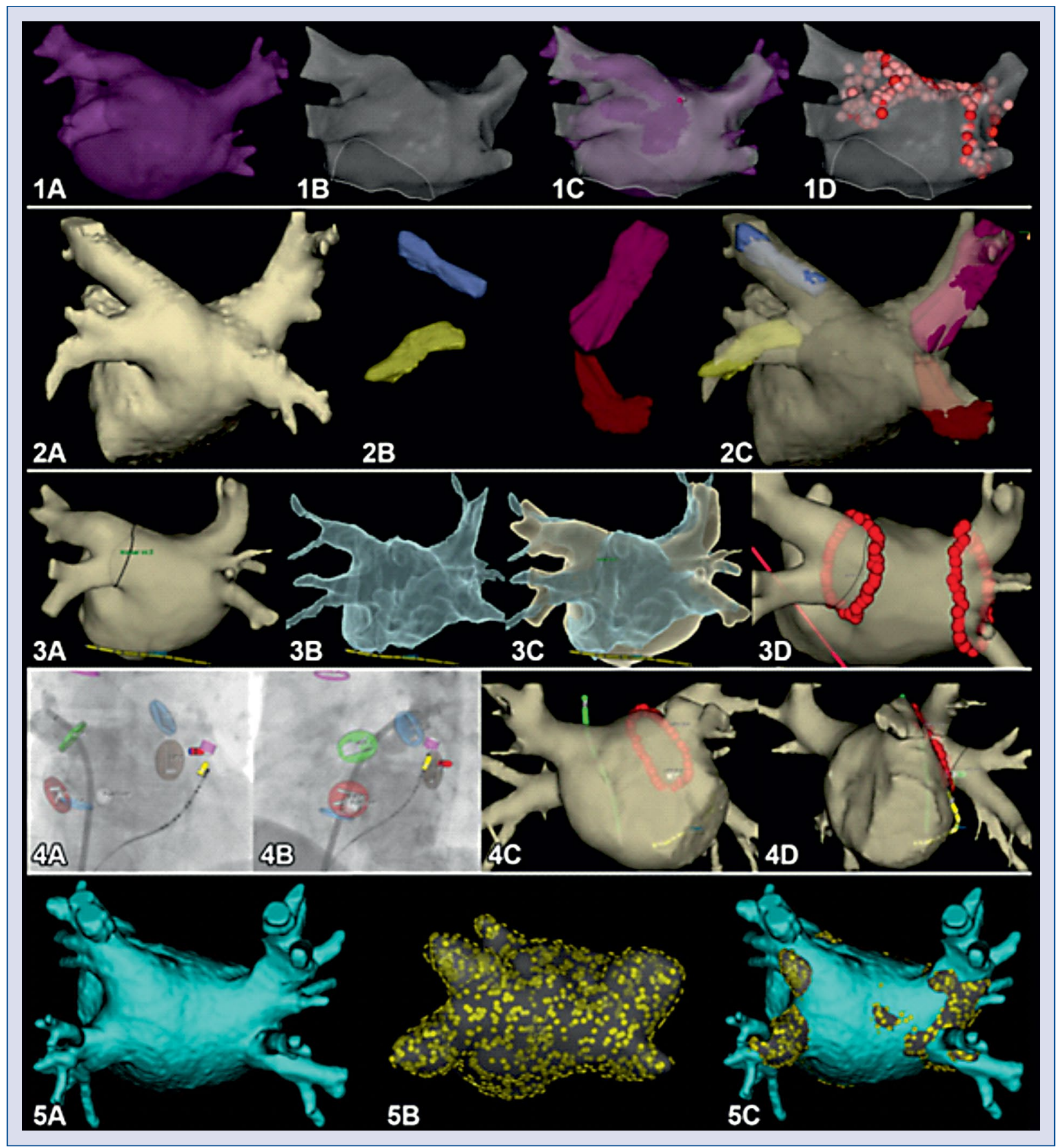

Figure 1. Workflow of the different electroanatomical mapping systems. Panel 1A-D. CARTO ${ }^{\circledR}$, 1A. Segmented $^{2}$ computed tomography (CT) shell of the left atrium; 1B. Reconstructed map by fast anatomical mapping; 1C. Fusion of the models by surface merging after setting a landmark at the posterior wall; 1D. Automatic visualization of ablation points by the VISITAG tool without any additional steps of registration. Panel 2A-C. EnSite NavX ${ }^{\circledR} 2005-2008$; 2A. Segmented CT of the left atrium; 2B. Reconstruction of each pulmonary vein as separate geometry; 2C. Registration of the reconstructed three-dimensional shell in the electroanatomical mapping system. Panel 3A-D. EnSite Velocity ${ }^{\circledR}$ 2008-2016; 3A. Segmented magnetic resonance imaging (MRI) of the left atrium; 3B. Reconstruction of the left atrium and each pulmonary vein in one map; 3C. Fusion of 3A and 3B by fiducial points; 3D. Registered MRI shell with ablation points (red) projected on the 3D shell; Panel 4A-D. EnSite Velocity ${ }^{\circledR}$ supported by MediGuide ${ }^{\circledR}$; 4A, B. Snapshots of simultaneously displayed MediGuide ${ }^{\circledR}$ pre-recorded fluoroscopy loops in a right anterior oblique view $(\mathbf{A})$ and left anterior oblique view $(\mathbf{B})$ and corresponding location of the catheter ablation tip in the EnSite Velocity ${ }^{\circledR}$ supported map (C, D). The circular markers tag ostia of pulmonary veins after localization by contrast-enhanced angiography (A, B); Panel 5A-C. Rhythmia ${ }^{\circledR}$; 5A. Segmented MRI of left atrium; 5B. Reconstruction of left atrium and each pulmonary vein; 5 C. Fusion of map $5 A$ and $5 B$. 
Table 1. Baseline characteristics.

\begin{tabular}{lcccccc}
\hline Variable & $\begin{array}{c}\text { All } \\
\text { (n = 9754) }\end{array}$ & $\begin{array}{c}\text { CARTO }^{\circledR} \\
(\mathbf{n}=\mathbf{4 2 2 9})\end{array}$ & $\begin{array}{c}\text { EnSite }^{\circledR} \\
(\mathbf{n}=\mathbf{4 5 1 0})\end{array}$ & $\begin{array}{c}\text { MediGuide }^{\circledR} \\
\text { (n= 853) }\end{array}$ & $\begin{array}{c}\text { Rhythmia }^{\circledR} \\
\text { (n= 162) }\end{array}$ & P $^{(\mathbf{n}=10.3}$ \\
\hline Age [years] & $66.6 \pm 10.3$ & $67.1 \pm 10.2$ & $66.7 \pm 10.2$ & $63.4 \pm 10.3$ & $65.3 \pm 10.3$ & $<0.001^{*}$ \\
Male sex & $6332(65)$ & $2751(65)$ & $2893(64)$ & $597(70)$ & $94(58)$ & $0.002^{+}$ \\
Hypertension & $6741(69)$ & $2850(67)$ & $3244(72)$ & $542(64)$ & $108(66)$ & $<0.001^{\S}$ \\
Diabetes mellitus & $1575(16)$ & $645(15)$ & $801(18)$ & $107(13)$ & $24(15)$ & $<0.001^{\S}$ \\
CAD & $1425(15)$ & $638(15)$ & $673(15)$ & $91(11)$ & $24(15)$ & $0.008^{*}$ \\
Heart failure & $2595(27)$ & $1100(26)$ & $1252(28)$ & $193(23)$ & $50(31)$ & $0.007^{+}$ \\
Paroxysmal AF & $5995(62)$ & $2734(65)$ & $2815(62)$ & $396(46)$ & $50(31)$ & $<0.001^{+}$ \\
Non-paroxysmal AF & $3759(38)$ & $1495(35)$ & $1699(38)$ & $457(54)$ & $113(69)$ & $<0.001^{+}$ \\
\hline
\end{tabular}

Continuous data are represented as mean \pm standard deviation and categorical data as number (percentage). P-values are given as overall value within the whole cohort; *Level of significance reached due to the MediGuide ${ }^{\circledR}$ group; +Level of significance reached due to the MediGuide $^{\circledR}$ and Rhythmia ${ }^{\circledast}$ group; ${ }^{\S}$ Level of significance reached between each group; AF — atrial fibrillation; CAD — coronary artery disease

pensation of cardiac and respiratory motion, an intracardiac reference catheter is usually placed into the coronary sinus.

At the beginning of the EnSite $\mathrm{NavX}^{\circledR}$ supported RFA for AF, the workflow was to reconstruct the $4 \mathrm{PVs}$ separately followed by a transmission into a pre-recorded CT or MRI model of the patient. A reconstruction of the atrium as well as PVs in one map was not possible (Fig. 1:2A-C). Since the introduction of EnSite Velocity ${ }^{\circledR}$ as a next generation in 2008, the system allowed a reconstruction of the PVs as well as the whole atrium in one map followed by a merge with the CT or MRI. Thereafter registration steps of the merged map to confirm its accuracy were necessary (Fig. 1: 3A-D).

Since the introduction of EnSite Precision ${ }^{\circledR}$ in 2016, which provides magnetic catheter information as well, no fundamental technological differences are present between the systems at present.

\section{MediGuide ${ }^{\circledR}$ technology}

In 2011, the MediGuide ${ }^{\circledR}$ technology (Abbott/St. Jude Medical, St. Paul, MN, USA) was introduced and became a standard in the present institution. By electromagnetic sensor-embedded catheter tracking in prerecorded fluoroscopy loops, the system allows additional X-ray imaging information as well as integration of a PV angiography [16]. Working in combination with EnSite ${ }^{\circledR}$, it represents a combination of magnetic and impedance based tools that had been available for years before the introduction of EnSite Precision ${ }^{\circledR}$ in 2016 (Fig. 1: 4A-D).

\section{Rhythmia ${ }^{\circledR}$}

The recently developed EAMS Rhythmia Mapping ${ }^{\circledR}$ (Boston Scientific, Marlborough, Massa- chusetts, USA) uses both magnetic and impedance information. The most important innovation of this system is an automatic record of high-resolution electroanatomical maps without manual annotation of the mapping points [17]. For RFA of AF, the workflow is to reconstruct the left atrium using a specially-designed mini basket (IntellaMap Orion ${ }^{\circledR}$ ) followed by visual alignment with the pre-recorded CT/MRI shell (Fig. 1: 5A-C).

\section{Statistical analysis}

All analyses were performed using SPSS version 20.0 for Windows (SPSS Inc., Chicago, IL, USA). Continuous data with a normal distribution are reported as a mean and standard deviation. Discrete variables are reported as frequency (percentage). Groups were compared using the $\chi^{2}$ test for categorical variables and ANOVA for continuous data. Bonferroni adjustment for multiple testing was done for post-hoc tests. All tests were performed two-tailed at significance level $\alpha=1 \%$ $(p<0.01)$ due to the high number of patients.

\section{Results}

\section{Baseline characteristics}

From January 2004 to December 2016, 9754 patients underwent interventional RFA for AF in this institution. The most frequently used mapping systems were the $\mathrm{CARTO}^{\circledR}$ system with $4229 / 9754(43 \%)$ cases and the EnSite ${ }^{\circledR}$ system with $4510 / 9754$ (46\%). 853/9754 (9\%) of the procedures were supported by MediGuide ${ }^{\circledast}$ technology and $162 / 9754(2 \%)$ by Rhythmia ${ }^{\circledR}$.

The patient cohort had a mean age of $66.6 \pm$ \pm 10.3 years and were $65 \%$ male, presenting with paroxysmal $\mathrm{AF}$ in $62 \%$ of cases (Table 1). As for 


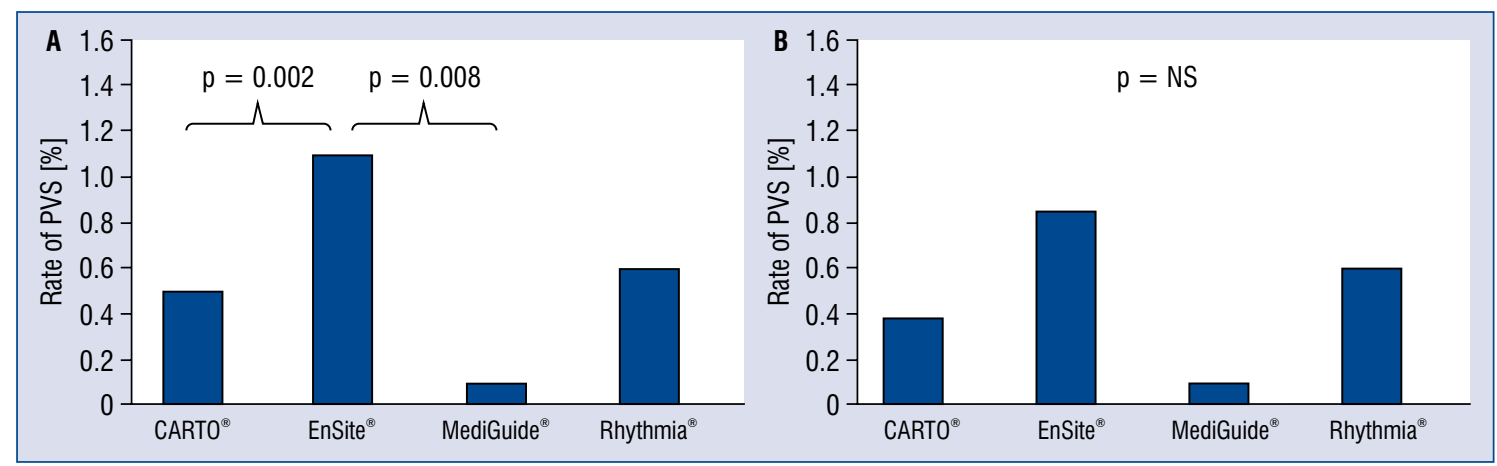

Figure 2. Rates and significance levels of pulmonary vein stenoses referred to the used mapping system in total (A) and since 2009 (B); PVS — pulmonary vein stenosis. The level of significance was only reached in CARTO ${ }^{\circledR}$ vs. EnSite ${ }^{\circledR}$ and EnSite ${ }^{\circledast}$ vs. MediGuide ${ }^{\circledR}$ in total. Since 2009, no significant difference between technologies was found.

general cardiac risk factors, arterial hypertension was present in $69 \%$ of patients, diabetes mellitus in $16 \%$, coronary artery disease in $15 \%$, and heart failure in $27 \%$. The distributions of these risk factors were statistically significant, with the difference being mainly driven by the MediGuide ${ }^{\circledR}$ group. These patients were healthier with regards to their cardiovascular risk factors but with a higher amount of persistent $\mathrm{AF}$. In comparing the baseline characteristic between CARTO $^{\circledR}$ and EnSite ${ }^{\circledR}$, the level of significance was only reached for arterial hypertension and diabetes mellitus (data not shown).

\section{Overall rate of PVS}

Out of 9754 interventional RFA for AF, a total of 70 patients with PVS were identified. The overall PVS rate at the present institution is $0.72 \%$. During the TEE screening period (group A), 9/1223 $(0.74 \%)$ patients with PVS were identified vs. $61 / 8531(0.72 \%, \mathrm{p}=0.972)$ without routine screening by TEE and CT/MRI (group B).

\section{Rate of PVS referred to mapping system}

The rate of PVS revealed a significant difference referred to the applied mapping system: $20 / 4229(0.5 \%)$ for CARTO $^{\circledast}$ vs. $48 / 4510(1.1 \%)$ for EnSite $^{\circledR}$ vs. $1 / 853(0.1 \%)$ for MediGuide ${ }^{\circledR}$ and $1 / 162$ $(0.6 \%)$ for Rhythmia ${ }^{\circledast}$ cases $(\mathrm{p}<0.001)$ (Fig. 2$)$.

The significance level was due to the difference between the CARTO $^{\circledast}$ vs. EnSite $^{\circledast}$ cases as well as the EnSite $^{\circledR}$ vs. the MediGuide ${ }^{\circledast}$ cases in the whole cohort (Fig. 2).

The curve of incidence rates related to the year of RFA procedure showed for EnSite ${ }^{\circledast}$ mapping a peak around 2007 whereby in this year the number of EnSite ${ }^{\circledast}$ supported procedures was relatively small. In comparison, the $\mathrm{CARTO}^{\circledR}$ group showed a relatively stable percentage (Fig. 3). Since 2009, there was an alignment of the curves without a statistical difference in the PVS rate (Figs. 2, 3).

The mean degree of stenosis between the EnSite $^{\circledast}$ and CARTO ${ }^{\circledast}$ group was $63 \pm 28 \%$ narrowing vs. $72 \pm 24 \%(\mathrm{p}=0.184)$ and the amount of treated PVS with $31 \%$ vs. $30 \%(\mathrm{p}=1.0)$ was equal.

\section{Discussion}

The overall PVS rate for approximately 10,000 $\mathrm{RFA}$ procedures of $\mathrm{AF}$ is $0.72 \%$ in the present institution. Since the change from ablation in or near the PVs to wide circumferential antral lesions, as well as the use of 3D mapping systems, the incidence of PVS has decreased from initially $6.3 \%$ (estimated from publications between 1999 and 2004) [18] to $1 \%$ [1, 4]. Compared to the reported data, the present single-center PVS rate reflects a comparable level.

Interestingly, routine screening using TEE and CT/MRI did not influence the percentage of identified PVS. Even though some asymptomatic PVS may have remained undiagnosed in group B, it was clinically reasonable to stop routine screening given the fact that no treatment would have been performed in these asymptomatic patients.

Referring to the applied mapping system used during the RFA procedure, the lowest cumulative PVS rate was revealed for MediGuide ${ }^{\circledast}$ cases with $0.1 \%$ and CARTO $^{\circledast}$ cases with $0.5 \%$. The overall PVS rate of EnSite $^{\circledast}$ cases was significantly higher with $1.1 \%$, although since 2009 an alignment of PVS rates was recorded. There are several different explanations for this result.

Technical background. Before introducing the new Precision platform in 2016, EnSite techno- 


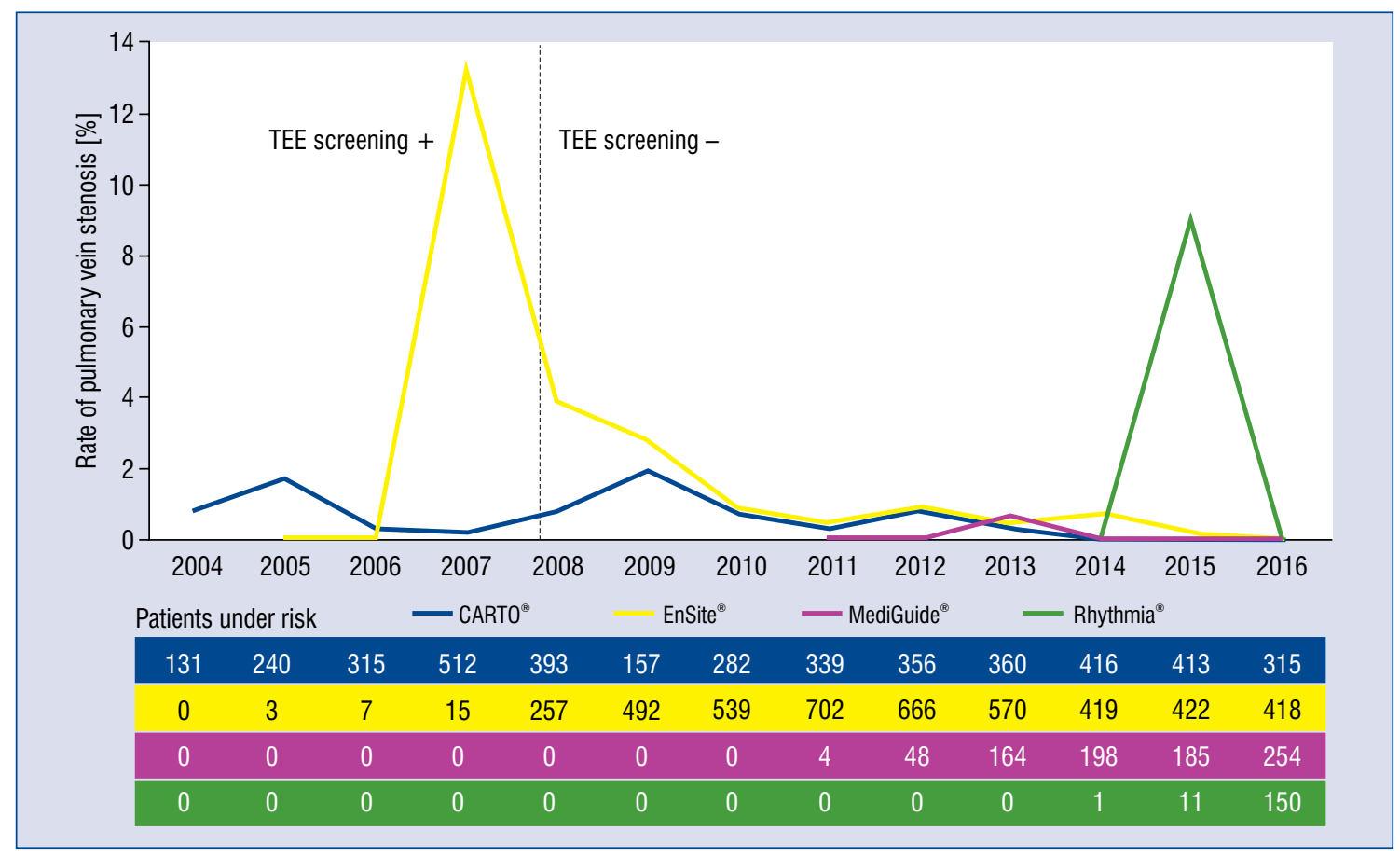

Figure 3. Rates of pulmonary vein stenoses referred to mapping systems and year of occurrence; TEE - transesophageal echocardiography.

logy was based exclusively on electrical information for catheter localization. The potential limitation of this technology is its dependency on the body's non-linear impedance distribution. Starting in 2008, the next generation system EnSite Velocity ${ }^{\circledast}$ was enabled to correct for this using a computer algorithm called "field scaling". Another frequent observation was mapshifting after patient motion or dislocation of the reference electrode. In contrast, CARTO ${ }^{\circledR}$ technology was impedance-based as well as electromagnetic-based. In a phantom experiment a significantly better point localization by CARTO $^{\circledR}$ in comparison to EnSite Velocity ${ }^{\circledR}$ could be demonstrated [19].

A randomized comparison of CARTOmerge ${ }^{\circledR}$ vs. EnSite $\mathrm{NavX}^{\circledR}$ in RFA for AF could demonstrate a significantly higher accuracy in lesion distance to the shell: $2.0 \mathrm{~mm}$ vs. $3.4 \mathrm{~mm}$ [20].

MediGuide ${ }^{\circledast}$ technology is a non-fluoroscopic catheter tracking system which works in combination with EnSite $^{\circledast}$ [21]. Because of the fact that MediGuide $^{\circledast}$ itself is electromagnetic based, the EnSite $^{\circledR}$ system was functionally upgraded to a combined impedance and electromagnetic mapping tool. Its accuracy was shown to be superior to EnSite ${ }^{\circledast}$ only in a phantom [22].
Since the introduction of EnSite Precision ${ }^{\circledR}$ in 2016, no fundamental technological differences between the competing systems are present to date.

Reconstruction and map fusion. Significant differences existed in the workflow with regards to EAM tools. The first version of EnSite $\mathrm{NavX}^{\circledR}$ was not able to reconstruct the whole atrium and PVs in one map. Furthermore, the lack of a field scaling algorithm often resulted in a flattened version of the left atrial anatomy. So it might be conceivable that inclusion of reconstructed PV's with their orifices into pre-recorded CT was imprecise. Since 2008 with the next version EnSite Velocity ${ }^{\circledR}$, this problem was solved which might be a reason for the decrease in PVS rates since then. To integrate the reconstructed map into the pre-recorded CT/MRI shell, some fiducial points must be chosen in both. Due to the subjective election of its localization, it appears as a source of error.

On the other hand, reconstruction of the whole atrium and PVs in one map and a subsequent operator-independent surface merging with pre-recorded $\mathrm{CT} / \mathrm{MRI}$ as the workflow of the $\mathrm{CARTO}^{\circledR}$ system right from the beginning could contribute to less registration errors and consequently lower PVS rates.

Registration. After map fusion by several fiducials, the EnSite ${ }^{\circledast}$ system required a further 
registration step to validate the map. It should be noted that a single incorrect registration point could produce a shifted map with unprecise localization of the PV ostia. There are data showing a higher precision of the surface-merge without a subsequent registration step for the CARTO ${ }^{\circledR}$ system in comparison to the point-by-point technique of EnSite ${ }^{\circledR}$ [19]. The values ranged from $0.73 \mathrm{~mm}$ for CARTO3 ${ }^{\circledR}$ vs. $2.02 \mathrm{~mm}$ for EnSite Velocity ${ }^{\circledR}$.

In comparison, MediGuide technology unifies additional anatomical information of a PV angiography whereas PV ostia are tagged by setting markers in pre-recorded cine loops.

Operator experience. Knowledge of anatomical orientation as well as know-how in the workflow of the different EAMS and their pitfalls might influence the rate of PVS substantially.

With only a small number of Rhythmia ${ }^{\circledR}$ supported cases performed, a fundamental statement seems to be unreasonable. Prior data did not show a difference in registration accuracy between pre-recorded CT or MRI for AF ablation procedures [23].

\section{The influence of screening for the rate of PVS}

In group A (year 2004-2007), over 1000 consecutively screened patients by TEE a PVS rate of $0.74 \%$ was evidenced. There was no significant difference in comparison to the period without screening in group B. TEE was shown to have a sensitivity of $84 \%$ and specificity of $98 \%$ in detecting moderate PVS and appears to be a useful diagnostic tool [24, 25]. Nevertheless, measurements of flow parameters and PV diameters are not accurate, especially of inferior PVs due to an unfavorable Doppler angle. Furthermore, detection of mild PVS remains a challenge [24].

However, there is no doubt that the rate of PVS is underestimated because of asymptomatic PVS and lack of routine screening. Obviously the PVS rate is influenced by factors such as energy titration, registration steps, and operator experience rather than on routine TEE screening. According to the current Consensus Statement on catheter and surgical ablation of AF from 2017, a routine screening for PVS after PV isolation is not recommended [12].

The opinion herein, is that routine screening is not necessary because patients with severe PVS, but no symptoms, would not be treated particularly with regard to the risk-benefit balance. Despite a well-known increase of morbidity due to PVS, there is actually no data showing a higher mortality.

\section{Limitations of the study}

The baseline characteristics between the groups of different EAMS are not balanced because of the retrospective nature of this registry analysis. However, there is no data showing an influence of cardiovascular comorbidities on the rate of PVS. There may be selection bias due to preference of the operators to different EAMS and varying levels of experience leading to an influence on PVS rates. Furthermore, when the MediGuide ${ }^{\circledR}$ was introduced, operators were already experienced with the EnSite ${ }^{\circledast}$ EAMS. Additionally, the study was performed in a single high-volume center with extensive experience in ablation of AF. As such, these data may not be easily applicable in cases of less experienced operators. Hence, analysis of experience from other centers would be desirable.

\section{Conclusions}

According to available research, this is the first analysis of the rate of PVS in a cohort of almost 10,000 patients. It was demonstrated that equal PVS rates, with and without screening, show significant differences between commonly used EAMS and the incidence of PVS after RFA for AF. Apart from technological differences between the EAMS, variances in workflow as well as operator experience might be influencing factors. Furthermore, the incorporation of new technologies seems to be associated with higher incidences of PVS before workflows are optimized.

Conflict of interest: Gerhard Hindricks has received a research grant by St. Jude Medical. Philipp Sommer received lecture fees by St. Jude Medical and Biosense Webster is member of the advisory board of St. Jude Medical and received a research grant by St. Jude Medical.

\section{References}

1. Cappato R, Calkins H, Chen SA, et al. Worldwide survey on the methods, efficacy, and safety of catheter ablation for human atrial fibrillation. Circulation. 2005; 111(9): 1100-1105, doi: 10.1161/01.CIR.0000157153.30978.67, indexed in Pubmed: 15723973.

2. McWilliams E, Giles J, Furniss S. Pulmonary vein stenosis may still occur after ablation. Europace. 2010; 12(8): 1097, doi: 10.1093/europace/euq118, indexed in Pubmed: 20421222.

3. Fender EA, Widmer RJ, Holmes DR, et al. Severe pulmonary vein stenosis resulting from ablation for atrial fibrillation: presentation, management, and clinical outcomes. Circulation. 2016; 134(23): 1812-1821, doi: 10.1161/CIRCULATIONAHA.116.021949, indexed in Pubmed: 27793993. 
4. Teunissen C, Velthuis BK, Hassink RJ, et al. Incidence of pulmonary vein stenosis after radiofrequency catheter ablation of atrial fibrillation. JACC Clin Electrophysiol. 2017; 3(6): 589-598, doi: 10.1016/j.jacep.2017.02.003, indexed in Pubmed: 29759432.

5. Holmes DR, Monahan KH, Packer D. Pulmonary vein stenosis complicating ablation for atrial fibrillation: clinical spectrum and interventional considerations. JACC Cardiovasc Interv. 2009; 2(4): 267-276, doi: 10.1016/j.jcin.2008.12.014, indexed in Pubmed: 19463436.

6. Prieto LR, Schoenhagen P, Arruda MJ, et al. Comparison of stent versus balloon angioplasty for pulmonary vein stenosis complicating pulmonary vein isolation. J Cardiovasc Electrophysiol. 2008; 19(7): 673-678, doi: 10.1111/j.1540-8167.2008.01110.x, indexed in Pubmed: 18284494.

7. De Potter TJR, Schmidt B, Chun KR, et al. Drug-eluting stents for the treatment of pulmonary vein stenosis after atrial fibrillation ablation. Europace. 2011; 13(1): 57-61, doi: 10.1093/europace/euq419, indexed in Pubmed: 21088005.

8. Schoene K, Arya A, Jahnke C, et al. Acquired pulmonary vein stenosis after radiofrequency ablation for atrial fibrillation: single-center experience in catheter interventional treatment. JACC Cardiovasc Interv. 2018; 11(16): 1626-1632, doi: 10.1016/j. jcin.2018.05.016, indexed in Pubmed: 30139470.

9. Schoene K, Sommer P, Arya A, et al. Complex cases of acquired pulmonary vein stenosis after radiofrequency ablation: is surgical repair an option? EP Europace. 2018, doi: 10.1093/europace/ /euy017.

10. Earley MJ, Showkathali R, Alzetani M, et al. Radiofrequency ablation of arrhythmias guided by non-fluoroscopic catheter location: a prospective randomized trial. Eur Heart J. 2006; 27(10): 1223-1229, doi: 10.1093/eurheartj/ehi834, indexed in Pubmed: 16613932.

11. Sra J, Krum D, Hare J, et al. Feasibility and validation of registration of three-dimensional left atrial models derived from computed tomography with a noncontact cardiac mapping system. Heart Rhythm. 2005; 2(1): 55-63, doi: 10.1016/j.hrthm.2004.10.035, indexed in Pubmed: 15851266.

12. Calkins H, Hindricks G, Cappato R, et al. 2017HRS/EHRA/ /ECAS/APHRS/SOLAECE expert consensus statement on catheter and surgical ablation of atrial fibrillation: Executive summary. EP Europace. 2017; 20(1): 157-208, doi: 10.1093/europace/ /eux275.

13. Rolf S, Kircher S, Arya A, et al. Tailored atrial substrate modification based on low-voltage areas in catheter ablation of atrial fibrillation. Circ Arrhythm Electrophysiol. 2014; 7(5): 825-833, doi: 10.1161/CIRCEP.113.001251, indexed in Pubmed: 25151631.

14. Gepstein L, Hayam G, Ben-Haim SA. A novel method for nonfluoroscopic catheter-based electroanatomical mapping of the heart. In vitro and in vivo accuracy results. Circulation. 1997; 95(6): 1611-1622, indexed in Pubmed: 9118532.

15. Wittkampf FH, Wever EF, Derksen R, et al. LocaLisa: new technique for real-time 3 -dimensional localization of regular intracar- diac electrodes. Circulation. 1999; 99(10): 1312-1317, indexed in Pubmed: 10077514.

16. Fenici R, Brisinda D. From 3D to 4D imaging: is that useful for interventional cardiac electrophysiology? Conf Proc IEEE Eng Med Biol Soc. 2007; 2007: 5996-5999, doi: 10.1109/ /IEMBS.2007.4353714, indexed in Pubmed: 18003380.

17. Nakagawa H, Ikeda A, Sharma T, et al. Rapid high resolution electroanatomical mapping: evaluation of a new system in a canine atrial linear lesion model. Circ Arrhythm Electrophysiol. 2012; 5(2): 417-424, doi: 10.1161/CIRCEP.111.968602, indexed in Pubmed: 22392447.

18. Rostamian A, Narayan SM, Thomson L, et al. The incidence, diagnosis, and management of pulmonary vein stenosis as a complication of atrial fibrillation ablation. J Interv Card Electrophysiol. 2014; 40(1): 63-74, doi: 10.1007/s10840-014-9885-z, indexed in Pubmed: 24626996.

19. Bourier F, Fahrig R, Wang P, et al. Accuracy assessment of catheter guidance technology in electrophysiology procedures: a comparison of a new 3D-based fluoroscopy navigation system to current electroanatomic mapping systems. J Cardiovasc Electrophysiol. 2014; 25(1): 74-83, doi: 10.1111/jce.12264, indexed in Pubmed: 24102965.

20. Finlay MC, Hunter RJ, Baker V, et al. A randomised comparison of Cartomerge vs. NavX fusion in the catheter ablation of atrial fibrillation: the CAVERN Trial. J Interv Card Electrophysiol. 2012; 33(2): 161-169, doi: 10.1007/s10840-011-9632-7, indexed in Pubmed: 22119854.

21. Sommer P, Rolf S, Piorkowski C, et al. Nonfluoroscopic catheter visualization in atrial fibrillation ablation: experience from 375 consecutive procedures. Circ Arrhythm Electrophysiol. 2014; 7(5): 869-874, doi: 10.1161/CIRCEP.114.001542, indexed in Pubmed: 25038922.

22. Bourier F, Reents T, Ammar-Busch S, et al. Sensor-Based Electromagnetic Navigation (Mediguide ${ }^{\circledR}$ ): How Accurate Is It? A Phantom Model Study. J Cardiovasc Electrophysiol. 2015; 26(10): 1140-1145, doi: $10.1111 /$ jce.12741, indexed in Pubmed: 26086594.

23. Dong J, Dickfeld T, Dalal D, et al. Initial experience in the use of integrated electroanatomic mapping with three-dimensional MR/ CT images to guide catheter ablation of atrial fibrillation. J Cardiovasc Electrophysiol. 2006; 17(5): 459-466, doi: 10.1111/j.15408167.2006.00425.x, indexed in Pubmed: 16684014.

24. Schneider C, Ernst S, Malisius R, et al. Transesophageal echocardiography: a screening method for pulmonary vein stenosis after catheter ablation of atrial fibrillation. Eur J Echocardiogr. 2006; 7(6): 447-456, doi: 10.1016/j.euje.2006.03.008, indexed in Pubmed: 16697260.

25. Stavrakis S, Madden GW, Stoner JA, et al. Transesophageal echocardiography for the diagnosis of pulmonary vein stenosis after catheter ablation of atrial fibrillation: a systematic review. Echocardiography. 2010; 27(9): 1141-1146, doi: 10.1111/j.15408175.2010.01250.x, indexed in Pubmed: 20678129. 